\title{
Por que o construtivismo náo funciona? Evolução, processamento de informaçáo e aprendizagem escolar
}

Why constructivism does not work? Evolution, information processing and school achievement

Vitor Geraldi Haase ${ }^{\mathrm{I}}$

Annelise Júlio-Costa ${ }^{\mathrm{I}}$

Júlia Beatriz Lopes Silva ${ }^{\mathrm{I}}$

\section{Resumo}

O construtivismo é a principal ideologia educacional contemporânea que influencia o pensamento pedagógico. Tal ideologia propóe que a aprendizagem deve acontecer através da experiência. De acordo com ela, a função da educação não diz tanto respeito à instrução ou aquisição de conhecimento, mas sim à formação em caráter mais amplo. Entretanto, as evidências indicam o fracasso do uso do construtivismo como estratégia pedagógica. O trabalho objetiva, através de uma revisão crítica, discutir aspectos que questionam a real validade do construtivismo: confusão entre pedagogia e epistemologia, aprendizagem ativa, evolução da mente humana, arquitetura cognitiva, diferenças individuais e fornecimento de diretrizes para operacionalização da aprendizagem. A revisão aponta que os métodos instrucionais precisam ser revalorizados, principalmente quando se trata da aprendizagem por crianças com dificuldades.

Palavras-chave: construtivismo; psicologia cognitiva; psicologia evolucionista.

\section{Abstract}

Constructivism is the main contemporary educational ideology that influences the pedagogical thinking. This ideology proposes that learning should be experience-based. According to it, the function of education is not mainly about instruction or knowledge acquisition, but it educates in a broader sense. However, evidences indicate the failures of the constructivism as a pedagogical strategy. The study aims, by means of a critical review, at discussing issues that question the constructivism validity: confusion between epistemology and pedagogy, active learning, human mind evolution, cognitive architecture, individual differences and guidelines for learning operationalization. The review indicates that the instructional methods need to be revalued, especially when it concerns children with learning difficulties.

Keywords: constructivism; cognitive psychology; evolutionary psychology.

$\overline{{ }^{\mathrm{I}} \text { Universidade Federal de }}$ Minas Gerais (Belo Horizonte), Brasil

Aliado à ideologia do politicamente correto, o construtivismo constitui a filosofia educacional predominante desde meados do Século XX. O construtivismo é uma praga que viceja mundo afora, mas seus efeitos são especialmente daninhos no Brasil. Suas consequências podem ser aferidas pelos indicadores do fracasso escolar brasileiro (desempenho em provas internacionais, analfabetismo funcional, etc.) bem como pelos altos índices de violência e criminalidade nas escolas e na sociedade em geral. É como se o Brasil estivesse formando coortes sucessivas de analfabetos funcionais e morais.

O descalabro faz os educadores reagirem com desamparo. A reaçáo das autoridades educacionais oscila entre a indiferença, à direita, e a justificação ideológica, à esquerda. Disfarçando em ambos os casos a má fé sob a forma de um discurso politicamente correto. A raiz do problema deve ser procurada na falta de formação dos educadores e na aderência mais ou menos rígida às doutrinas do construtivismo. O construtivismo precisa ser escrutinado porque é a filosofia ou ideologia predominante na formação dos educadores brasileiros e está na origem do seu despreparo. Para comprovar isto, basta um exemplo muito simples. Examine o currículo de graduação em pedagogia da sua universidade. Aposto que você constatará que o currículo é estruturado com referência em três autores: Henri Wallon (1879-1962), Lev Vygotsky (1896-1934) e Jean Piaget (1896-1980). O mais novo deles morreu há mais de trinta anos. Skinner é uma espécie de Belzebu, que precisa ser evitado e/ou exorcizado a todo custo. Sobre ciência cognitiva, nem uma palavra. É como se a psicologia cognitiva e a neuropsicologia nunca tivessem existido ou tivessem congelado nestes três autores clássicos. A formação psicológica do pedagogo brasileiro fica reduzida ao estudo da história das idéias em psicologia educacional na primeira metade do Século XX. Por exemplo, Muniz, Silva e Coutinho (2013) analisaram os planos de ensino de 617 cursos de pedagogia no Brasil e constataram que apenas dois contemplavam tópicos relacionados à neuropsicologia e às neurociências. 
Antes de examinar os problemas com o construtivismo é preciso, entretanto, descrever, ainda que brevemente, no que consiste esta ideologia educacional. O construtivismo tem sua origem na ideologia romântica de autores tais como Jean-Jacques Rousseau (1712 - 1778 - Rousseau, 1979). De maneira simplificada, Rousseau negava a existência de uma natureza humana. É como se, ao nascimento, o cérebro humano fosse uma espécie de tabula rasa, uma lousa em branco sobre a qual a cultura fosse paulatinamente escrevendo através da educação. $\mathrm{O}$ indivíduo é apenas um produto do seu meio. $\mathrm{E}$ ao estado cabe o direcionamento, para bem ou para mal, do processo.

A negaçáo da natureza humana e a atribuição de um papel preponderante ao estado permitiram que, em muitos casos, as ideias rousseaunianas se aliassem ao marxismo (Bernardin, 2012). A educação é vista, neste caso, como um veículo para a transformação ou revolução social. O produto final almejado é a abolição da estrutura de classes e a dominação total da sociedade pelo estado. Neste caso, a meta final da educação é a "construção de um novo homem/mulher socialista”. Um ser angelical, desprovido das contradições inerentes à natureza humana, e dócil aos ditames do estado. É aí que entra a lavagem cerebral da correção política. Conforme Pinker (2002), essa perspectiva remonta a Rousseau e corresponde ao chamado "modelo-padrão das ciências sociais", o qual ilumina diversas correntes na psicologia e pedagogia, principalmente as variantes sócio-históricas do construtivismo.

De uma ou de outra forma, todos os autores construtivistas são caudatários deste ideal rousseauniano. $\mathrm{O}$ construtivismo representa também uma reação ao ensino tradicional, baseado na autoridade e "decoreba”. O objetivo era estimular o desenvolvimento de metodologias que tornassem a aprendizagem mais atraente para as crianças e jovens, mais próximas do seu contexto de vida e mais lúdicas. São privilegiadas as abordagens pedagógicas as quais enfatizam o papel ativo da criança na aprendizagem, ou na "construçáo do conhecimento", como se fala em "pedagoguês castiço". O indivíduo é concebido como totipotente, sendo dotado de recursos inesgotáveis de criatividade e para a aprendizagem de quaisquer fatos, conceitos ou habilidades. Os construtivistas e pedagogos de um modo geral adoram a tal teoria das inteligências múltiplas de Gardner (Gardner \& Hatch, 1989), a qual anda na contramáo da pesquisa psicométrica sobre inteligência (Visser, Ashton \& Vernon, 2006). Segun- do Gardner, quase tudo representa alguma forma de inteligência, desde as habilidades intra- e interpessoais até as habilidades musicais e esportivas. Algumas pessoas podem ser menos dotadas em algum domínio, mas certamente poderão desenvolver seus talentos em outros. A teoria psicométrica da inteligência é bem mais complexa. Existe um tal de "g" ou fator geral da inteligência, o qual permeia o desempenho em múltiplos domínios e constitui uma commodity relativamente escassa.

Que o construtivismo fracassou, é sabidamente conhecido (Kirshner, Sweller \& Clark, 2006). Há muito tempo. Mayer (2004) observou que desde a década de 1950 o construtivismo vem sendo operacionalizado sob diferentes nomes nos EUA, tais como discovery learning, inquiry-based learning, problem-based learning, experiential learning, minimally-guided instruction, etc.. À medida que vão se acumulando as evidências quanto ao fracasso desta doutrina, a reação dos educadores tem sido a de mudar sucessivamente o rótulo, mas continuar oferecendo o mesmo produto. Como não é possível discutir os detalhes técnicos desta literatura no contexto do presente artigo, basta mencionar os resultados de uma meta-análise conduzida por Alfieri, Brooks, Aldrich e Tenenbaum (2011). Para fins de operacionalização, o construtivismo foi definido neste estudo como minimally guided instruction: instruçâo minimalista, baseada na filosofia de propiciar situaçóes problema e materiais, deixando que as crianças se virem por conta própria. Ou seja, "instrução" sem instrução. Os resultados foram impressionantes. A minimally-guided instruction foi inferior à abordagem instrucional em 580 comparaçóes realizadas, com um magnitude de efeito $\mathrm{d}=-0,38$. Por outro lado, a aprendizagem baseada na descoberta aliada à tutoria (enhanced discovery) foi superior a todos os outros métodos em 360 comparaçôes $(\mathrm{d}=0,30)$. A conclusão é inevitável de que o ensino eficiente não pode prescindir de algum grau de tutoria ou instrução formal.

Os resultados destas e outras pesquisas têm sido divulgados nos principais periódicos científicos da área de psicologia educacional. Mas têm sido solenemente ignorados pelos educadores e autoridades educacionais no Brasil. Os motivos mais profundos devem ser procurados na sociologia e na política (Bernardin, 2012). O que tentaremos fazer a seguir é analisar as razóes deste fracasso, à luz da psicologia cognitiva e da psicologia evolucionista. As razóes psicológicas para o fracasso do construtivismo serão abordadas em seis tópicos. 


\section{O construtivismo confunde pedagogia com epistemologia}

A preocupação epistemológica dos teóricos construtivistas é inegável e se baseia na metáfora do aprendiz como epistemólogo (Piaget, 2003). O construtivismo pressupóe que a abordagem da criança a situaçóes-problema é similar àquela de pesquisadores e profissionais adultos, constituindo uma importante janela para a investigação epistemológica da construção do conhecimento. Nada mais falso. A pesquisa cognitiva demonstra que noviços e peritos diferenciam-se brutalmente quanto ao modo com que se debruçam sobre os problemas (Kirshner, Sweller \& Clark, 2006; Sweller, Ayres \& Kalyuga, 2011; Willingham, 2011). As diferenças não são tanto de estilos de raciocínio, mas quanto ao nível de conhecimentos acumulado. O grande mestre difere do enxadrista de fim de semana, menos por sua habilidade excepcional de raciocínio e memória de trabalho, e mais pelo conhecimento acumulado sobre as jogadas possíveis (Chase \& Simon, 1973). Face a uma jogada determinada, o noviço precisa utilizar-se de recursos de processamento controlado, engajando-se em um processo laborioso de solução de problemas para encontrar a solução. $\mathrm{O}$ grande mestre, por sua vez, apenas precisa reconhecer um padrão de jogada para ativar automaticamente na sua memória de longo prazo os desfechos possíveis, tendo o melhor lance à sua disposição no estoque de conhecimentos disponíveis.

As pesquisas em psicologia e neurociência cognitiva corroboram a hipótese de que a aprendizagem depende de um processo exaustivo de prática, o qual permite que a abordagem aos problemas mude qualitativamente da tentativa e erro e/ou processamento controlado para o resgate automático da melhor solução (Zamarian, Ischebeck, \& DeLazer, 2009). Williams James (1989) comentou que a educação é um processo de formação de hábitos. A pessoa educada é um homem com bons hábitos. Quanto mais rotinas comportamentais o indivíduo desenvolver, quanto mais problemas ele consegue resolver no piloto automático, mais recursos de processamento estarão disponíveis para a solução de problemas crescentemente mais complexos ou para o lazer.

Ignorar as diferenças entre noviços e peritos significa impor uma demanda excessiva para os alunos, superior à sua capacidade. Os efeitos motivacionais são desastrosos, bem como os resultados em termos de aprendizagem. Enfatizar a "compreensão" menosprezando a "decoreba" priva a criança de automatizar o acesso a fatos e procedimentos essenciais para a aprendizagem de questóes mais complexas.

\section{$O$ construtivismo confunde dimensóes da aprendizagem ativa}

A confusão entre dimensões da atividade na aprendizagem foi sublinhada por Mayer (2004). Segundo este autor, o papel ativo do aprendiz é essencial. Mas a atividade pode ser comportamental (externamente observável) ou cognitiva (internalizada, e não observável externamente). Os resultados da pesquisa cognitiva mostram claramente que a eficiência da aprendizagem depende do engajamento do aluno, do nível de codificação e elaboração cognitivas alcançado com o material a ser aprendido (Kirshner, Sweller \& Clark, 2006; Sweller, Ayres \& Kalyuga, 2011; Willingham, 2011). O construtivismo privilegia a atividade comportamental. Os alunos são estimulados a se engajarem ativamente com problemas, a buscarem soluçóes, a procurarem e construírem materiais, a interagirem em grupo, etc.. A atividade comportamental frenética pode ocorrer, entretanto, às expensas da atividade cognitiva. E isto resulta em prejuízo da aprendizagem. O importante é promover a atividade cognitiva, a qual não se traduz necessariamente em atividade comportamental.

A confusão entre atividade comportamental e cognitiva é reminiscente de uma piada feita por Russell (1927) após visitar diversas universidades norte-americanas de elite. Questionando-se sobre as diferenças entre os EUA e a Europa, Russell propôs que a diferença entre os ratos fora o que mais lhe havia despertado a atenção. Colocados em um labirinto, os ratos americanos ficavam correndo freneticamente de um lado para o outro, até que encontravam o reforço. Os ratos europeus, por sua vez, ficavam quietinhos pensando, até encontrarem a solução. Entáo, iam diretamente até o local onde se encontrava a recompensa. As crianças e professoras submetidas ao regime construtivista se assemelham aos ratos americanos, ou a baratas tontas que se póem a correr de um lado para outro, sem uma diretriz, sem um método que não seja a tentativa e erro. A atividade comportamental pode mascarar a falta de atividade cognitiva. Por outro lado, a atividade cognitiva pode ser um prazer furtivo e solitário. 


\section{O construtivismo ignora a natureza evoluída da mente humana}

A mente humana não é uma tabula rasa, mas reflete o longo processo de evolução da nossa espécie por seleção natural e sexual. Cada sistema cognitivo do qual dispomos representa uma adaptação que emergiu em nossos ancestrais como resposta a alguma pressão de seleção. Uma das principais pressôes de evolução na espécie humana foi a socialidade (Geary, 2005; Mithen, 1998). A vida em grupo exige cogniçáo social, tanto para competir quanto para cooperar. Uma relação linear pode ser observada entre o tamanho da horda e indicadores do tamanho cerebral (Dunbar, 2003). A partir das complexidades e imprevisibilidade da vida social, surgiu a necessidade de integração de sistemas cognitivos modulares e relativamente independentes. Emergiu, então, a inteligência geral, um dispositivo computacional mais complexo, que funciona como uma espécie de resolvedor geral dos problemas.

As habilidades cognitivas podem ser categorizadas em biologicamente primárias e biologicamente secundárias (Geary, 2007; 2008). As habilidades primárias correspondem aos sistemas modulares especializadas, os quais evoluíram para manejar os problemas regularmente enfrentados por nossos ancestrais no ambiente em que a espécie evoluiu. Os principais sistemas cognitivos nucleares lidam com o selfe com o grupo (folk psychology), com os recursos naturais (folk biology) e com o ambiente físico (folk physics). Tais sistemas constituem o equipamento padrão da espécie. A perícia nos domínios folk-psychologies é adquirida de forma natural, não havendo necessidade de instrução formal. A motivação para aprendizagem nestes domínios é intrínseca e o resultado é uma espécie de caixa de ferramentas mentais, um conjunto de heurísticas que são automaticamente ativadas sempre que se fizerem necessárias. Exemplos de domínios primários são o reconhecimento de faces, a linguagem oral e a aritmética intuitiva, tais como senso numérico, contagem e operaçóes elementares (Haase, Ferreira, Moura, Pinheiro-Chagas \& Wood, 2012).

As habilidades biologicamente secundárias evoluíram em resposta às situaçóes do ambiente que se caracterizam por maior variabilidade e imprevisibilidade. E em nenhum outro domínio a variabilidade e imprevisibilidade são tão grandes quanto na cognição social. A partir de um determinado momento na evolução, a espécie humana adquiriu supremacia sobre os recursos ecológicos (Alexander, 1979). Desde então as principais pressóes evolutivas na nossa espécie dizem respeito aos desafios colocados pela cooperação e competição intraespecífica (Geary, 2005). A resposta a estas pressóes foi a evolução de uma ferramenta cognitiva mais poderosa, a inteligência geral ou fator "g", a qual emergiu a partir da integraçáo sucessiva de sistemas modulares. Um aspecto em especial da inteligência geral, a inteligência fluída, permite ao individuo resolver de forma estratégica problemas com os quais nem ele nem a espécie haviam se defrontado anteriormente (Geary, 2005). Mas este sistema tem seu custo. Ele funciona de forma lenta, laboriosa, tem capacidade limitada e é muito mais susceptível a erro. Todas características que correspondem àquilo que, em psicologia, se chama atualmente de processamento controlado ou funçôes executivas.

A inteligência geral e os domínios biologicamente secundários estão na raiz da evoluçáo cultural (Geary, 2005; 2007; 2008). Mas a perícia nestes domínios requer um longo e laborioso processo de aprendizagem, para a qual é imprescindível a instrução formal. Também não existe uma motivação intrínseca para aprender nos domínios biologicamente secundários. A motivação precisa ser aprendida, constituindo-se um domínio secundário de motivação para o desempenho acadêmico. Os motivos para aprendizagem nos domínios primários precisam ser transferidos para aquisição de controle no domínio social, qualificando o individuo para interaçóes sociais mais complexas, tanto cooperativas quanto competitivas. Sáo exemplos de domínios secundários a aprendizagem da leitura, o uso da leitura para a aprendizagem e aspectos mais formais da aritmética tais como tabuada dos fatos aritméticos, valor posicional e algoritmos de cálculo (Haase, Ferreira, Moura, Pinheiro-Chagas \& Wood, 2012).

O ritmo acelerado de evolução cultural foi gradualmente impondo um descompasso entre as demandas do ambiente atual por habilidades secundárias e as habilidades primárias com as quais fomos equipados no ambiente ancestral (Geary, 2007; 2008). A perícia nas habilidades primárias não é garantia de adaptação social na cultura contemporânea. O sucesso cooperativo e competitivo exigem atualmente perícia em uma série de domínios secundários. Perícia esta que somente é adquirida às custas de muito esforço e instrução formal, não havendo um sistema motivacional intrínseco que regule sua aquisição.

A massa de informação cultural acumulada impóe demandas cognitivas crescentes em termos de 
habilidades secundárias. Nem todos os indivíduos conseguem responder a estas demandas. A tragédia do construtivismo consiste no fato de que a aprendizagem social, em um contexto natural e informal é suficiente para aquisição de perícia nos domínios primários, mas não nos domínios secundários. Ou seja, o construtivismo é bom para que as crianças aprendam aquilo que aprenderiam de qualquer maneira sem instrução formal (Haase, Ferreira, Moura, PinheiroChagas \& Wood, 2012). Mas não tem como ler para aprender sem haver automatizado a leitura de palavras isoladas. Tampouco é possível progredir na matemática sem haver automatizado os fatos aritméticos e os algoritmos de cálculo.

Algumas correntes construtivistas, tais como a pedagogia do oprimido (Freire, 1981), se ocuparam destas dificuldades que uma fracçáo significativa e crescente da populaçáo, principalmente de menor poder aquisitivo, enfrenta na aprendizagem das habilidades secundárias. A ideia é enriquecer os materiais e práticas de ensino com conteúdos que se assemelhem mais à experiência de vida destes indivíduos. Só que isto náo funciona. Para servir-se da leitura para a aprendizagem, o indivíduo precisa primeiro aprender a ler (Florit \& Cain, 2011, Gough, 1996). $\mathrm{E}$ jamais vai conseguir isto iniciando-se por textos, que até podem ser dotados de maior familiaridade e significado pessoal, mas que lhes permanecem inacessíveis. A aprendizagem da leitura requer o domínio sobre as correlaçóes grafema-fonema e a automatização do reconhecimento visual de palavras isoladas. Este processo requer da criança e das professoras três anos em média de trabalho árduo (Dehaene, 2012). Exigir compreensão de textos antes que a criança tenha adquirido alguma proficiência na leitura de palavras é colocar a carroça na frente dos bois. A ignorância dos resultados de pesquisa científica sobre alfabetização, tais como descritos, por exemplo, por Morais (2013), é certamente um dos ingredientes principais do fracasso escolar brasileiro.

\section{O construtivismo ignora as restriçóes à aprendizagem impostas pela arquitetura cognitiva humana}

A ferramenta mais poderosa para caracterizar a arquitetura cognitiva da mente humana contemporânea foi propiciada pela teoria do processamento de informação (Kirshner, Sweller \& Clark, 2006; Mayer, 2008; Sweller, Ayres \& Kalyuga, 2011; Willingham, 2011). Uma distinção fundamental é realizada en- tre a memória de curto prazo e a memória de longo prazo. A capacidade de armazenamento temporário na memória de curto prazo associada às operaçóes de controle compóe a memória operacional, correspondendo à memória de acesso aleatório de um computador digital e constituindo o locus princeps de processamento e aprendizagem. A aprendizagem a longo prazo depende da elaboração e codificação da informação na memória de curto de prazo. A memória operacional corresponde a todos os processos psicológicos aos quais temos acesso introspectivo, consciente imediato, ao chamado momento psicológico (James, 1989). A codificação e elaboração na memória de curto prazo constituem processos laboriosos, que demandam recursos atencionais e estão sujeitos a erro. A característica mais importante da memória de trabalho diz respeito à sua limitação, tanto no que se refere à duração, quanto à capacidade de armazenamento e processamento. Passado algum tempo a informação se esvanece e a aprendizagem fica prejudicada. Da mesma forma, quando a memória operacional é sobrecarregada a eficiência de aprendizagem também diminui.

A memória de longo prazo corresponde ao nosso estoque de conhecimentos. Algumas das principais características da memória de longo prazo são sua diversidade de conteúdos, duração temporal indefinida, capacidade praticamente ilimitada e natureza associativa e reconstrutiva (Eysenck \& Keane, 2010). Vários tipos de conhecimentos relevantes do ponto de vista da aprendizagem são armazenados na memória de longo prazo: fatos, conceitos, procedimentos, hábitos. O sucesso da aprendizagem é medido em última análise pelo grau em que a memória de longo prazo é modificada. A diversidade de conteúdos se reflete na aritmética, por exemplo, através dos conceitos de número e operaçôes, procedimentos de cálculo e fatos aritméticos (Haase, Ferreira, Moura, PinheiroChagas \& Wood, 2012). A aritmética constitui um todo complexo e integrado. $\mathrm{O}$ indíviduo necessita adquirir perícia em todos estes domínios. Não basta compreender, há a necessidade de automatizar o acesso aos fatos e a implementaçáo dos algoritmos.

A memória de longo prazo não é um armazém passivo, mas um sistema complexo e altamente dinâmico que desempenha um papel fundamental na aprendizagem (Sweller, Ayres \& Kalyuga, 2011). Sua natureza associativa explica as razóes pelas quais a aprendizagem nova é facilitada pela aprendizagem prévia. Quanto mais conhecimento estiver disponível mais fácil, rápida e eficiente será a assimilação de 
novos conteúdos. Por esta razão não basta "compreender" é necessário incorporar a informação nova à velha, elaborando-a e codificando-a.

Os processos de elaboração e codificação se refletem na natureza reconstrutiva da memória de longo prazo. A memória está sendo constantemente reestruturada, à medida que novas informaçóes são elaboradas e codificadas. O sono REM também desempenha um papel importante na aprendizagem a longo prazo, constituindo uma espécie de mecanismo de desfragmentação do hardware (Breton \& Robertson, 2013). A memória de trabalho desempenha um papel importante no resgate e processamento da informação disponível na memória de longo prazo. Mas a elaboração e codificação na memória de longo prazo estão ocorrendo o tempo todo, independentemente do acesso e elaboração mentais conscientes.

$\mathrm{O}$ que acontece quando os humanos se defrontam com um problema? Segundo Willingham (2011), a memória de trabalho é ativada e inicia-se uma busca pela solução na memória de longo prazo. Quando não existe uma solução disponível na memória de longo prazo, que possa ser automaticamente ativada, inicia-se uma busca pela solução no ambiente. É apenas quando a busca na memória de longo prazo e no ambiente é infrutífera que os humanos se póem a pensar. Pensar é trabalhoso, custa energia e muito sujeito a limitaçóes de capacidade e erro. A motivação é a fonte energética que mantém a memória de trabalho ligada (Willingham, 2011). Ficamos felizes sempre que podemos funcionar no piloto automático, sempre que conseguimos resolver um problema sem precisar pensar.

A aprendizagem depende de um equilíbrio entre compreender e decorar. A "decoreba" náo pode ser menosprezada. Apenas compreender, sem incorporar nova informação à memória de longo prazo não resulta em aprendizagem. É justamente o que acontece com a instrução minimalista. Ao sonegar informaçóes cruciais para a criança, o construtivismo coloca-a em uma situação de atenção dividida (Kirshner, Sweller \& Clark, 2006; Sweller, Ayres \& Kalyuga, 2011). A criança precisa dividir recursos cognitivos preciosos e escassos entre a busca pela solução do problema e a memorização. O resultado final é que, quando a solução para o problema é encontrada às custas de muito esforço e tentativa e erro, a aprendizagem se torna menos eficiente do ponto de vista de modificação estrutural na memória de longo prazo. Será que o modo mais eficiente de transmitir o legado cultural de uma geração para outra é esperar que cada indivíduo reinvente a roda por sua conta (Matthews, 2002)? Ou será que os educadores não poderiam facilitar a vida das crianças, ensinando-lhes da melhor maneira possível o que eles próprios já sabem e assim liberando espaço de processamento para a descoberta do que ainda não se sabe?

\section{O construtivismo ignora as diferenças individuais}

A variabilidade é a característica mais saliente dos processos biológicos. Como os processos psicológicos também são resultado da evolução biológica, não poderiam deixar de se caracterizar pela variabilidade. Múltiplas são as dimensões psicológicas variáveis que afetam a aprendizagem escolar. Cada uma destas é afetada por influências genéticas e ambientais compartilhadas e não-compartilhadas (Willcutt et al., 2010). Dados de análise multinível mostram que as características individuais explicam uma percentagem expressivamente maior no desempenho escolar do que características relacionadas à escola ou classe (Trembaly, Ross, \& Berthelot, 2001). Por outro lado, os estudos genético-quantitativos descobriram que o desempenho escolar depende tanto da herdabilidade quanto das influências ambientais (Willcutt et al., 2010). Os fatores ambientais podem ser categorizados em compartilhados (aqueles que tornam os irmáos mais semelhantes entre si) e não compartilhados (aqueles que tornam os irmãos mais diferentes entre si). A herdabilididade explica de 55 a $65 \%$ por cento da variância no desempenho, respectivamente, em aritmética e leitura. Os fatores ambientais compartilhados respondem por $15 \%$ da variância, enquanto as influências ambientais não compartilhadas explicam fatias de 20 a $25 \%$ da variância no desempenho, respectivamente em leitura e aritmética. Em amostras com menor heterogeneidade sócio-econômica a herdabilidade aumenta. Em amostras com maior diversidade social a herdabilidade diminui (Turkheimer, 2000).

Além da herdabilidade, características ambientais também se associam com o desempenho escolar. Uma meta-análise identificou correlaçóes de $r=0,22$ tomando o indivíduo como unidade de análise e de $\mathrm{r}=0,55$ tomando a família como unidade de análise para a associação entre nível sócio-econômico e desempenho escolar e de $\mathrm{r}=0,73$ para características do ambiente familiar e desempenho escolar (White, 1982). 
A influência ambiental sobre o desempenho escolar precisa, entretanto, ser qualificada por três resultados fundamentais da genética comportamental (Plomin, DeFries, Knopik \& Neiderhiser, 2012):

1) a herdabilidade cresce e a influência do ambiente compartilhado diminui à medida que o indivíduo se desenvolve;

2) a influência do ambiente não-compartilhado aumenta à medida que o tempo passa;

3) existe uma correlação genético-ambientais, ou seja, determinadas características individuais, principalmente de personalidade, tornam o indivíduo mais exposto a determinados tipos de experiências.

A principal dimensão de variabilidade interindividual com potencial para afetar a aprendizagem escolar é a inteligência geral. O fator "g" da inteligência pode explicar quase $60 \%$ por cento da variância no desempenho escolar em aritmética e 48\% em língua nativa (Deary, Strand, Smith, \& Fernandes, 2007). Mas habilidades específicas também são importantes. Cada uma das dimensóes psicológicas que afetam o desempenho escolar se caracteriza por uma distribuição normal. Os transtornos do desenvolvimento e de aprendizagem correspondem ao extremo esquerdo da distribuição normal. Não existe descontinuidade entre as distribuiçôes. Os mesmos fatores genéticos e ambientais que influenciam o desenvolvimento típico de habilidades também determinam o seu transtorno (Plomin \& Kovas, 2005). Dentre as principais dimensôes psicológicas específicas com potencial para afetar o desempenho escolar podem ser citados exemplos, acompanhadas de alguns dos reconhecidos transtornos na nosologia psiquiátrica ${ }^{1}$ (APA, 2013):

- Temperamento e funçôes executivas (Transtorno do Déficit de Atenção e Hiperatividade, Transtorno Desafiador-Opositivo);

- Processamento fonológico (Transtorno de aquisição da linguagem oral, Dislexia);

- Senso numérico (Discalculia);

- Habilidades visoespaciais (Transtorno não-verbal de aprendizagem);

- Coordenaçáo motora (Transtorno do desenvolvimento da coordenação motora);

- Habilidades sociais (Autismo).

1 É importante ressaltar que as dimensôes mencionadas não constituem uma lista exaustiva, não apresentam uma relaçáo biunívoca simples com os transtornos associados, nem tampouco esgotam o leque de endofenótipos constitutivos dos diversos transtornos.
O construtivismo privilegia, por exemplo, a aprendizagem colaborativa em detrimento da instrução formal (Tomasello, Kruger \& Ratner, 1993). $\mathrm{Na}$ instrução formal, o grosso da intencionalidade vai do professor para o aluno. Já na aprendizagem colaborativa, a intencionalidade é bidirecional, fluindo de um colaborador para outro. A instrução formal impóe, portanto, menos demandas cognitivas para o aluno do que a aprendizagem colaborativa. Esta análise sugere que se tenha certa cautela na prescrição $\mathrm{da}$ aprendizagem colaborativa para alunos que apresentem dificuldades em algum domínio do funcionamento cognitivo ou social. A aprendizagem colaborativa pode lhes exigir mais do que conseguem responder, contribuindo assim para a construção social de deficiências e cronificação de estresse e fracasso escolar. Por que simplesmente não ensinar as coisas para as crianças que apresentam dificuldades? Poupando-lhes trabalho e o constrangimento do fracasso em aprender por conta própria ou na interação com colegas? Colegas dos quais a crianças com dificuldades são frequentemente as vítimas de bullying.

O currículo escolar é planejado para atender às demandas dos $2 / 3$ de indivíduos cujo desempenho situa-se próximo à média em cada uma destas dimensôes. As professoras não sabem muito bem o que fazer com os meninos que náo acompanham o currículo e com aqueles para os quais o currículo é fácil demais. Isto se deve a um dilema imposto por ocasião da universalização da educação escolar na virada do Século XIX para o Século XX. As turmas poderiam ser segregadas por nível de habilidade ou por idade. Mas não há como fugir da diversidade interindividual. A opção política que se afirmou nos últimos 100 anos foi segregar os alunos em turmas conforme a idade. Os alunos progridem de série mesmo que não demonstrem avanços correspondentes do desempenho. Com isto, evita-se o trauma da repetência e os alunos dificuldades continuam acompanhando e socializando com seus colegas que estáo acompanhando o currículo. $\mathrm{O}$ resultado disto sáo turmas altamente heterogêneas do ponto de vista do desempenho cognitivo e acadêmico. Atender às necessidades desta diversidade de perfis exigiria uma política educacional baseada na avaliaçáo do desempenho e individualização do currículo.

A inadequação curricular é uma agravante das dificuldades enfrentadas pelas crianças com dificuldades de aprendizagem. As dificuldades crônicas de aprendizagem constituem um fator de risco para 
problemas psiquiátricos, tais como baixa autoestima, ansiedade, depressão ou comportamentos antissociais (Auerbach, Gross-Tsur, Manor \& Shalev, 2008). $\mathrm{Na}$ perspectiva construtivista, a diversidade individual é solenemente ignorada. Caso fosse considerada, o ensino se tornaria uma missão impossível, uma vez que o construtivismo não está equipado com as necessidades de avaliação e planejamento curricular indispensáveis a um ensino individualizado.

A negligência das diferenças individuais se traduz em manifestaçóes, p. ex., como a campanha contra a suposta medicalização do ensino (Frias \& Júlio-Costa, 2013). As entidades nosológicas com potencial para afetar o desempenho escolar são tratadas apenas como construçôes sociais, advindas das relaçôes de poder na sociedade. Diagnosticar as crianças como sendo portadoras de algum transtorno de aprendizagem passa a ser alguma coisa do mal, resultado das perversas maquinaçôes do sistema capitalista. A única solução aceitável para os problemas da educação é política. O resultado é uma dose extra de sofrimento para as crianças portadoras de alguma vulnerabilidade individual com potencial de afetar a aprendizagem escolar, bem como para suas famílias. E a situação é mais perversa ainda, uma vez que o sofrimento é maior para os mais pobres, para aqueles que não podem custear serviços especializados por conta própria.

\section{O construtivismo náo fornece diretrizes claras quanto à sua operacionalizaçáo}

O construtivismo possui várias facetas. Existem vários tipos de construtivismo construtivistas (Matthews, 2002), muitos dos quais contraditórios entre si. Algumas discussóes sobre que tipo de construtivismo fundamenta qual política educacional soam até mesmo meio bizantinas (Massabni \& Ravagni, 2008). Trata-se de uma filosofia educacional muito ampla, englobando uma ética, uma ontologia, uma epistemologia, etc.. As questôes relativas à técnica pedagógica ficam subespecificadas e raramente são investigadas com o rigor metodológico exigido das intervençôes comportamentais. A diversidade de práticas é grande e sua falta de fundamentação psicológica patente. Jenkins (2000) sugeriu que construtivismo funciona como um corpo de doutrina relativamente frouxo, uma ideologia, que serve para justificar as práticas em sala de aula dos professores. Práticas estas que são fundamentadas na intuição, convicçôes e experiências pessoais de cada professora. O construti- vismo é tão grandioso, abrange tantas e tão diversas coisas, que, às vezes, fico pensando: Será que ele não existe e nós podemos estar perdendo o nosso tempo?

A ênfase nas ideias construtivistas e no ideal politicamente correto torna a formação psicológica das professoras deficiente no que diz respeito às bases cognitivas e comportamentais da aprendizagem. As quais deveriam ser os fundamentos da prática instrucional. Um dos exemplos mais notórios é a falta de preparo para lidar com questóes disciplinares. Existe um fosso entre as boas intençóes politicamente corretas e a realidade do comportamento dos alunos em sala de aula e na escola. A falta de preparo das professoras para lidar de forma não coerciva com os comportamentos desafiadores e agressivos de muitos alunos coloca-as em uma situação de desamparo emocional, contribuindo para o agravamento de sintomas de estresse crônico. Ou então, com maior frequência do que seria desejável, as professoras recorrem a práticas punitivas de manejo da disciplina em sala de aula. Entra em cena o "construtivismo da reguada”, acentuando mais ainda o descompasso entre a teoria e a prática.

Muita confusão foi criada também em torno dos objetivos da escola. Os alvos postulados (relacionados à formação da cidadania, capacidade crítica, participação, etc.) soam táo grandiloquentes que contrastam com os resultados vexaminosos obtidos em medidas simples de desempenho escolar, tais como a leitura e a aritmética. Parece que a pedagogia padece de uma propensão nefelibata. Ela tem se envolvido com questôes filosóficas e políticas grandiosas, mas pode estar se descuidando do "feijáo com arroz" instrucional. Um exemplo disto são os tais temas transversais. $\mathrm{O}$ objetivo do ensino de matemática, por exemplo, não se restringe a apenas ensinar as crianças de $1^{\mathrm{a}}$ a $4^{\mathrm{a}}$ séries a fazer contas. Os objetivos são muito mais grandiosos. A matemática deve ser usada como veículo para trabalhar temas transversais tais como a cidadania, a participação social, a ética, o preconceito, etc. (Brasil, 1997). O resultado é que a pessoa sai da escola sem saber fazer troco, sendo presa fácil da anomia política e dos preconceitos de toda espécie. Talvez fosse o caso de repensar os objetivos educacionais. Menos pode ser mais. A consecução de objetivos mais modestos pode levar à postulação paulatina de objetivos mais ambiciosos. Um destes objetivos modestos diz respeito às práticas instrucionais e sua fundamentação psicológica. A escolha deste caminho é fundamentada empiricamente nos avanços das ciências cognitivas. 


\section{Referências}

Alexander, R. D. (1979). Darwinism and human affairs. Seattle: University of Washington Press.

Alfieri, L., Brooks, P. J., Aldrich, N. J., \& Tenenbaum, H. R. (2011). Does discovery-based instruction enhance learning?. Journal of Educational Psychology, 103(1), 1-18.

American Psychiatric Association - APA. (2013). DSM-5. Diagnostic and statistical manual of mental disorders ( $5^{\text {th }}$ ed.). Washington, DC: American Psychiatric Press.

Auerbach, J. G., Gross-Tsur, V., Manor, O., \& Shalev, R. S. (2008). Emotional and behavioral characteristics over a six-year period in youths with persistent and nonpersistent dyscalculia. Journal of learning disabilities, 41(3), 263-273.

Bernardin, P. (2012). Maquiavel pedagogo. Ou o ministério da reforma psicológica. Campinas: Ecclesia/Vide.

Brasil. Ministério da Educação e do Desporto. Secretaria de Educação Fundamental (1997). Introdução aos parâmetros curriculares nacionais. Brasília: Ministério da Educação e do Desporto.

Breton, J., \& Robertson, E. M. (2013). Memory Processing: The Critical Role of Neuronal Replay during Sleep. Current Biology, 23(18), R836-R838.

Chase, W. G., \& Simon, H. A. (1973). Perception in chess. Cognitive psychology, 4(1), 55-81.

Dehaene, S. (2012). Os neurônios da leitura: como a ciência explica a nossa capacidade de ler. Porto Alegre: Penso.

Deary, I. J., Strand, S., Smith, P., \& Fernandes, C. (2007). Intelligence and educational achievement. Intelligence, 35(1), 13-21.

Dunbar, R. I. (2003). The social brain: mind, language, and society in evolutionary perspective. Annual Review of Anthropology, 32, 163-181.

Eysenck, M. W., \& Keane, M. T. (2010). Cognitive psychology. A student's handbook ( $6^{\text {th }}$ ed.). Hove, UK: Psychology Press.

Florit, E., \& Cain, K. (2011). The simple view of reading: Is it valid for different types of alphabetic orthographies?. Educational Psychology Review, 23(4), 553-576.

Freire, P. (1981). Pedagogia do oprimido (9a. ed.). Rio de Janeiro: Paz e Terra.

Frias, L., \& Júlio-Costa, A. (2013). Os Equívocos e Acertos da Campanha" Não à Medicalização da Vida”. Psicologia em Pesquisa, 7(1), 3-12.
Gardner, H., \& Hatch, T. (1989). Educational implications of the theory of multiple intelligences. Educational researcher, 18(8), 4-10.

Geary, D. C. (2005). The origin of mind. Evolution, brain, cognition and general intelligence. Washington, DC: American Psychological Association.

Geary, D. C. (2007). Educating the evolved mind: Conceptual foundations for an evolutionary educational psychology. In: J. S. Carlson \& J. R. Levin (Eds.), Educating the evolved mind (pp. 1-99, Vol. 2, Psychological perspectives on contemporary educational issues). Greenwich, CT: Information Age.

Geary, D. C. (2008). An evolutionarily informed education science. Educational Psychologist, 43(4), 179-195.

Gough, P. B. (1996). How children learn to read and why they fail. Annals of Dyslexia, 46(1), 1-20.

Haase, V. G., Ferreira, F. O., Moura, R. J., PinheiroChagas, P. \& Wood, G. (2012). Cognitive neuroscience and math education: teaching what kids don't learn by themselves. International Journal for Studies in Mathematics Education, 5(2).

James, W. (1989). Princípios de psicología. México: Fondo de Cultura Económica. (Trabalho original de 1890).

Jenkins, E. W. (2000). Constructivism in school science education: powerful model or the most dangerous intellectual tendency? Science \& Education, 9(6), 599-610.

Kirschner, P. A., Sweller, J., \& Clark, R. E. (2006). Why minimal guidance during instruction does not work: An analysis of the failure of constructivist, discovery, problem-based, experiential, and inquiry-based teaching. Educational psychologist, 41(2), 75-86.

Massabni, V. G., \& Ravagnani, M. C. A. N. (2008). Progressão Continuada: qual construtivismo está em jogo? Paidéia (Ribeirão Preto), 18(41), 469-484.

Matthews, M. R. (2002). Constructivism and science education: a further analysis. Journal of Science Education and Technology, 11(2), 121-134.

Mayer, R. E. (2004). Should there be a three-strike rule against pure discovery learning? the case for guided methods of instruction. American Psychologist, 59(1), 14-19.

Mayer, R. E. (2008) Information procesing. In: T. L. Good, (Ed.) 21 ${ }^{\text {st }}$ Century education. A reference handbook (pp. 168-174). Los Angeles: Sage. 
Mithen, S. (1998). A pré-história da mente. Uma busca das origens da arte, da religião e da ciência. São Paulo: UNESP.

Morais, J. (2013). Alfabetizar para a Democracia. Porto Alegre: Penso

Muniz, M., da Silva, L. C., \& Coutinho, A. R. (2013). Análise de Planos de disciplinas relacionadas às neurociências, neuropsicologia e neuroeducação. Trilhas Pedagógicas, 3(3), 103-118.

Piaget, J. (2003). Biologia e conhecimento. Ensaio sobre as relaçóes entre as regulaçôes biológicas e os processos cognitivos. Petrópolis: Vozes.

Pinker, S. (2002). The blank slate. The modern negation of human nature. New York: Penguin.

Plomin, R., DeFries, J. C., Knopik, V. S., \& Neidehiser, J. M. (2012). Behavioral genetics $\left(6^{\text {th }}\right.$ ed.). New York: Worth.

Plomin, R., \& Kovas, Y. (2005). Generalist genes and learning disabilities. Psychological bulletin, 131(4), 592.

Rousseau, J. J. (1979). Emile or on education. New York: Basic Books.

Russell, B. (1927). Philosophy. New York: Norton.

Sweller, J., Ayres, P., \& Kalyuga, S. (2011). Cognitive load theory. New York: Springer.

Tomasello, M., Kruger, A. C., \& Ratner, H. H. (1993). Cultural learning. Behavioral and brain sciences, 16(03), 495-511.

Tremblay, S., Ross, N., \& Berthelot, J. M. (2001). Factors affecting grade 3 student performance in Ontatario: a multilevel analysis. Education Quarterly Review, 7(4), 25-36.

Turkheimer, E. (2000). Three laws of behavior genetics and what they mean. Current Directions in Psychological Science, 9(5), 160-164.

Visser, B. A., Ashton, M. C., \& Vernon, P. A. (2006). Beyond g: Putting multiple intelligences theory to the test. Intelligence, 34(5), 487-502.

White, K. R. (1982). The relation between socioeconomic status and academic achievement. Psychological Bulletin, 91(3), 461.

Willingham, D. T. (2011). Por que os alunos não gostam da escola. Porto Alegre: Artmed.

Willcutt, E. G., Pennington, B. F., Duncan, L., Smith, S. D., Keenan, J. M., Wadsworth, S., ... Olson, R. K. (2010). Understanding the complex etiologies of developmental disorders: behavioral and molecular genetic approaches. Journal of developmental and behavioral pediatrics: JDBP, 31(7), 533.
Zamarian, L., Ischebeck, A., \& Delazer, M. (2009). Neuroscience of learning arithmetic-evidence from brain imaging studies. Neuroscience \& Biobehavioral Reviews, 33(6), 909-925.

\section{Endereço para correspondência:}

Vitor Geraldi Haase

Avenida Antônio Carlos, 6627 - Pampulha FAFICH/ sala 2016

CEP:31270-901 - Belo Horizonte/MG

E-mail:vghaase@gmail.com

Recebido em 21/05/2014

Revisto em 03/01/2015

Aceito em 04/02/2015 